\title{
Acercamiento teórico a la constitucionalidad del sistema tributario colombiano*
}

[Artículos]

\author{
Sol Beatriz Vélez Escobar ${ }^{* *}$ \\ Ruby Stella Cabrera Jaramillo ${ }^{* * *}$ \\ José Wilmar Pino Montoya ${ }^{* * * *}$
}

Recibido: 10 de octubre de 2020

Aprobado: 30 de noviembre de 2020

Citar como:

Vélez Escobar, S. B., Cabrera Jaramillo, R. S. y Pino Montoya, J. W. (2021).

Acercamiento teórico a la constitucionalidad del sistema tributario colombiano.

Revista IUSTA, (54). https://doi.org/10.15332/25005286.5984

(c) $(9)$

\footnotetext{
* Este artículo es resultados de la investigación titulada "Percepción social de los pequeños contribuyentes acerca de la constitucionalidad del sistema tributario colombiano", avalada y financiada mediante número de radicado 55488, del 8 de octubre de 2018, por la Vicerrectoría de Investigaciones de la Universidad Católica Luis Amigó (Colombia), para ser desarrollado en el 2019.

** Magíster en dirección y administración de empresas. Docente de la Corporación Universitaria Minuto de Dios (Uniminuto), sede Bello, Colombia. Correo institucional: sbveleze@ucn.edu.co. ORCID: https://orcid.org/0000-0002-4146-6435

*** Magíster en Tributación y Política Fiscal. Docente de la Universidad Católica Luis Amigó (Colombia). Correo institucional: ruby.cabreraja@amigo.edu.co. ORCID: https://orcid.org/0000-0003-4505-382X

**** Doctor en Filosofía. Docente de la Universidad Católica Luis Amigó (Colombia). Correo institucional: jose.pinomo@amigo.edu.co. ORCID: https://orcid.org/00000001-9035-2058
} 


\section{Resumen}

Este artículo de reflexión es el resultado del proyecto de investigación

"Percepción social de los pequeños contribuyentes acerca de la constitucionalidad del sistema tributario colombiano", que tiene por objetivo general analizar la percepción social de los pequeños contribuyentes acerca de la constitucionalidad del sistema tributario colombiano. La investigación se realiza desde el enfoque cualitativo y desde una estrategia de estudio documental. En los resultados se aprecia la fundamentación constitucional del pago del impuesto colombiano y cómo este se concreta en el sistema tributario, lo que lo hace un sistema cambiante. Como conclusiones se logra visualizar la garantía del impuesto a partir de la constitución, la concreción de los fines del Estado con su cobro y la potestad de exigir el pago del justo tributo bajo el marco constitucional.

Palabras claves: constitución, contribuyente, pequeño contribuyente, sistema tributario colombiano, tributo.

\section{Theoretical approach to the constitutionality of the Colombian tax system}

\section{Abstract}

This reflection article is the result of the research project "Social perception of small taxpayers about the constitutionality of the Colombian tax system", which general objective is to analyze the social perception of small taxpayers about the constitutionality of the Colombian tax system. The research is carried out from a qualitative approach and from a documentary study strategy. The results show the constitutional basis for the payment of the Colombian tax and how this is materialized in the tax system, which makes it a changing system. As conclusions it is possible to visualize the guarantee of the tax from the constitution, the realization of the purposes of the State with its 
collection and the power to demand the payment of fair tax under the constitutional framework.

Keywords: constitution, taxpayer, small taxpayer, Colombian tax system, tax.

\section{Abordagem teórica da constitucionalidade do sistema tributário colombiano}

\section{Resumo}

Este artigo de reflexão é o resultado do projeto de pesquisa "Percepção social dos pequenos contribuintes sobre a constitucionalidade do sistema tributário colombiano", que tem o objetivo geral de analisar a percepção social dos pequenos contribuintes acerca da constitucionalidade do sistema tributário colombiano. A pesquisa é realizada sob a abordagem qualitativa e a partir de uma estratégia de estudo documental. Nos resultados, é considerada a fundamentação constitucional do pagamento do imposto colombiano e como este se concreta no sistema tributário, o que o torna um sistema oscilante. Como conclusões, é possível visualizar a garantia do imposto a partir da constituição, o cumprimento dos objetivos do Estado com sua cobrança e a potestade de exigir o pagamento do justo tributo sob o referencial constitucional.

Palavras-chaves: constituição, contribuinte, pequeno contribuinte, sistema tributário colombiano, tributo.

\section{Introducción}

La historia moderna enseña que el hombre es un ser vivo esencialmente sociable. En los textos de nuestra historia antigua se describen civilizaciones compuestas por miles y cientos de miles de seres humanos. Hasta nuestros días, seguimos viendo la tendencia natural del hombre al agruparse con el fin de procurarse el mayor bienestar para unos a otros y promocionar los diferentes tipos de intereses (Welte, 2004). 
"Los principios del liberalismo: individualismo, igualdad, imperio de la ley, constitucionalismo, división y equilibrio de poderes, poder político limitado, entre otros, son elementos básicos para la organización de las sociedades actuales" (Rodríguez, 2008, p. 7). Sin embargo, y a pesar de la gran ventaja que representan las herramientas en la vida del hombre, las condiciones geográficas, climáticas, psicológicas, etc., limitan su accionar de tal manera que este advierte la necesidad de conformar grupos, con el fin de repartir tareas y compartir esfuerzos, en aras de lograr una mayor eficiencia en la consecución de recursos necesarios para sobrevivir (Castro, 2016).

Entendido esto, se puede traer el concepto sobre el ciudadano en la sociedad moderna, que "es aquella persona que, con base en libertades y derechos reconocidos de manera constitucional, asume posturas activas para deliberar, analizar y argumentar sobre los compromisos que se generan en la vida pública" (Uvalle, 2006, p. 309). La lucha por la vida es constante.

La agrupación de los seres humanos, con el fin de repartir tareas y compartir esfuerzos, surge de la imposibilidad material de que un individuo emprenda y culmine todo tipo de proyectos, lo que lo aleja de alcanzar un mínimo bienestar individual y de disponer de tiempo libre. Dahl (1999) comprende la participación efectiva como la libertad de las personas de plasmar ideas que sean conocidas por el resto de los miembros del conjunto social.

$\mathrm{Al}$ ser conscientes de que es más fácil la realización de cualquier proyecto a través del trabajo en grupo, el hombre empezó a reunirse en tribus, clanes, naciones y poblaciones cada vez más numerosas. Pero siempre ha existido en el hombre una naturaleza egoísta, que busca la autoafirmación de la voluntad de cada individuo (Galán, 2017). 
Dado que el egoísmo del hombre impide que este apoye desinteresadamente al grupo al que pertenece, los distintos grupos de seres humanos han desarrollado a lo largo de la historia diferentes mecanismos para motivar en los hombres acciones dirigidas a procurar el mayor bienestar para el mayor número de individuos o, dicho de otro modo, acciones altruistas. Para alcanzar aquel bienestar, es preciso adoptar modelos de organización que permitan obtener la mayor eficiencia y eficacia en la administración de los recursos de todo el conglomerado social.

Uno de los mecanismos que dirigen las acciones humanas hacia el bienestar general es el tributo. A lo largo de los años, distintas culturas han apoyado su desarrollo y sostenimiento en este mecanismo: en unas, consistía en una cuota periódica que cada individuo pagaba de manera voluntaria a un fondo común y, en otras, dicha cuota debía cubrirse de manera obligatoria, so pena de recibir un castigo por el grupo al que se pertenecía. En la modernidad, los Estados ${ }^{1}$ continúan utilizando los tributos para financiar su sostenimiento y desarrollo. Colombia no es la excepción. Los tributos representan una importantísima fuente de recursos para el sostenimiento y desarrollo del Estado colombiano. Conforme a lo anterior, el diseño constitucional del tributo está basado en el concepto de autocontención, pero no siempre se comprende de esta manera. En efecto, la mencionada noción enlaza el interés recaudatorio con los derechos del contribuyente de ser gravado de forma justa y equitativa, por lo que cada norma tributaria debe interpretarse en una relación de fin a medios legítimos. Las entidades territoriales en Colombia

\footnotetext{
${ }^{1}$ Un Estado es un modelo de organización social, compuesto por tres elementos: población, territorio y soberanía.
} 
afrontan diversos problemas de financiamiento que les impiden cumplir con sus diferentes obligaciones y responsabilidades a nivel social Recordemos que los ingresos públicos se subdividen en ingresos corrientes y de capital. Los ingresos corrientes, a su vez, se subdividen en ingresos tributarios y no tributarios. Para el 2016 los ingresos corrientes en Colombia representaron el $59.4 \%$ de los ingresos totales; los ingresos tributarios representaron el $99.47 \%$ de los ingresos corrientes, mientras que los ingresos no tributarios apenas representan el $0.53 \%$ (Mesa, 2016).

Esto es una evidencia de la importancia que los tributos tienen en Colombia. Lamentablemente, no suele advertirse su valor y su impacto en la economía nacional y las consecuentes contingencias que se derivan para cada uno de los hogares y empresas colombianas (Romero-Molina et ál., 2013). La desatención que han recibido los tributos por la mayoría de los ciudadanos colombianos se debe, en gran parte, al complejo sistema normativo que, dicho sea de paso, es tan cambiante como un ser vivo. Este documento constituye un esfuerzo por acercar a cualquier persona, con una mediana motivación, al entendimiento de los principios, las normas y los procedimientos relevantes frente al impuesto de renta y complementarios, que representó en el 2018 el $21.7 \%$ de los ingresos tributarios, lo que lo convierte en el principal impuesto en Colombia. Es bien conocido que las normas tributarias son bastante cambiantes, ya que, cada vez que se promulga una nueva reforma tributaria, esta se basa en concentrar mayores recursos para la salud, educación y otros sectores que se ven impactados por los ciclos económicos. Advirtiendo este panorama, se procura estructurar unas bases conceptuales sólidas que luego le permitan al lector acercarse al estudio de cada reforma tributaria, a través de un método sistemático que facilite su comprensión y asimilación. 
Para ello, en este documento se empieza por delimitar conceptos importantes, tales como derecho, derecho tributario, norma, principio, Constitución y cultura de la Legalidad, entre otros. Posteriormente, se aborda el estudio de los principios que rigen el sistema tributario colombiano.

\section{Metodología}

Esta es una investigación descriptiva y analítica basada en el método cualitativo. Los estudios descriptivos consisten "en llegar a conocer las situaciones, costumbres y actitudes predominantes a través de la descripción exacta de las actividades, objetos, procesos y personas" (Sequeiros Pastor, 2015, p. 10). En un primer momento, se describe la revisión sistemática de literatura y se defiende cada una de las categorías de investigación; posteriormente, se identifica el método de análisis cualitativo que permita relacionar el impacto de los pequeños contribuyentes y el sistema tributario colombiano (Romero-Molina et ál., 2013).

En este sentido, el estudio se desarrolla bajo un enfoque cualitativo, porque busca describir y relacionar las diferentes categorías de investigación que influyen la constitucionalidad del sistema tributario colombiano, una aproximación desde la sociología fiscal a la observación de fuentes normativas y su análisis crítico, así como de la doctrina y la jurisprudencia relacionadas con el tema de estudio, seguidas de comentarios personales sobre asuntos generales y señalamientos sobre cuestiones concretas. Además, este enfoque tiene la simplicidad de extraer los conceptos que asemejan las personas a partir de lo que dicen y hacen según la percepción de los pequeños contribuyentes acerca de la constitucionalidad del sistema tributario colombiano. El proceso de indagación es inductivo, donde se buscan respuestas a preguntas que se 
centran en la experiencia social y de la vida humana (Romero-Molina et ál., 2013).

Este estudio está basado en la revisión de literatura que permite determinar el estado del arte sobre el análisis de los pequeños contribuyentes con relación a la constitucionalidad del sistema tributario en Colombia. Por lo tanto, se identifica material publicado que proporcione un análisis de la literatura reciente o actual sobre las implicaciones de estos contribuyentes sobre el sistema de tributación colombiano y su relación con la Constitución Política de Colombia. En este sentido, la revisión de la literatura consistió en buscar, seleccionar y consultar la bibliografía que pueda ser útil para este estudio. A partir de esto, se identifica una serie de documentos, seleccionando información relevante y necesaria sobre los sistemas de tributación y su relación con los pequeños contribuyentes, y sus requerimientos o planteamientos mínimos sujetos a las normas constitucionales.

Se selecciona material publicado reciente sobre sistemas tributarios y la implicación de los pequeños contribuyentes. Las publicaciones integran resultados sobre el tema de estudio, sea en el título, resumen o palabras clave. Las bases consultadas fueron las siguientes: Jstor, en donde se enfatiza en la búsqueda de Journal Economics y Policy Journal, dado que estas revistas proporcionan material sobre el tema de sistemas tributarios, al igual que Journal Economic and Financial Affairs de la European Commission; Google Scholar; la Comisión Económica para América Latina y el Caribe (CEPAL); y Organización para la Cooperación y Desarrollo Económicos (OCDE). Finalmente, se realizó la búsqueda en Handbook Oxford - Journals: The Oxford handbook of public policy.

Para los términos de búsqueda se utilizaron las siguientes palabras clave tanto en español como en inglés: derechos, sistemas de tributación, 
Constitución Política de Colombia, contribuyentes, normatividad y cultura de la legalidad. Los criterios de selección para la inclusión de los artículos fueron determinados mediante documentos completos que se referían a las palabras clave. Es decir, se incluirán los estudios que analicen tanto los sistemas de tributación como el impacto de los contribuyentes sobre los tributos y su relación con la Constitución Política de Colombia, lo que permitirá obtener una mirada sobre la problemática de la complejidad de los sistemas normativos en el país y su efecto sobre las contribuciones de los pequeños empresarios.

Los criterios de exclusión se aplican para aquellos documentos tales como informes de caso, opiniones de expertos publicadas como editoriales o cartas al editor, artículos metodológicos y estudios que relacionan la financiación con los logros de la salud pública. Además, se excluyen los documentos que en su resumen no proporcionen aportes a la problemática de la complejidad de los sistemas normativos en el país y su efecto sobre las contribuciones de los pequeños empresarios o no reúnan las palabras clave en su título o resumen. No se aplican restricciones por nacionalidad de los autores.

La selección de los artículos estuvo determinada por los criterios de inclusión y exclusión, los cuales se aplicaron inicialmente a los títulos y resúmenes de las referencias identificadas. Luego, se obtuvo el texto completo de los artículos que fueron incluidos y se aplicaron los mismos criterios al texto completo, para determinar finalmente cuáles se incluirían en la revisión de literatura. A partir de la revisión de literatura se elabora una síntesis de definiciones sobre reportes de casos relacionados con los sistemas tributarios, normativos y su impacto sobre los pequeños contribuyentes. 


\section{Marco contextual}

En la jerarquía del ordenamiento jurídico colombiano se establece la Constitución Política de 1991 como la norma de normas, es decir, como la norma suprema con respecto a la cual han de adecuarse las demás normas jurídicas. En Colombia, doctrinariamente se ha clasificado al conjunto de normas jurídicas de acuerdo con su naturaleza, procedimiento y materia de la que se ocupan. A partir del primer criterio - la naturaleza de las normas -, se distinguen dos grandes grupos, a saber: el derecho privado y el derecho público (Barragán, 2016).

El derecho privado está conformado, entre otros, por el derecho civil, el comercial, el laboral, etc. Al derecho público, por su parte, lo conforman, entre otros, el derecho constitucional, internacional público, penal, procesal, tributario o fiscal, etc.

De las anteriores ramas del derecho público, adquiere especial importancia el derecho tributario, entendido como aquél que regula las relaciones jurídicas entre el Estado y los particulares en materia fiscal. $\mathrm{Al}$ respecto, es preciso destacar que existen propuestas teóricas que enmarcan al derecho tributario como una rama del derecho administrativo; sin embargo, en el presente estudio se aborda como una rama independiente y autónoma, gracias a que cuenta con normas, principios y procedimientos propios.

$\mathrm{Al}$ estudiar el derecho tributario, así como cualquier otra rama del derecho, debe atenderse a los principios, objetivos, derechos y garantías que la Constitución Política de 1991 consagra en su cuerpo normativo, en tanto es la norma de mayor jerarquía y a la cual deben adaptarse todas las demás.

De los postulados normativos que contiene nuestra Carta Política, tienen especial importancia los principios constitucionales, de los cuales algunos han recibido consagración expresa en la Constitución y otros se entienden 
implícitos dentro de esta, sin que estén expresamente positivizados, tal como lo ha entendido la doctrina y la misma jurisprudencia de la Corte Constitucional y del Consejo de Estado (Cubides, 2018). Los principios constitucionales en Colombia adquieren una gran importancia, en tanto es a partir de esta que se orienta la búsqueda de la materialización del conjunto de derechos, objetivos y garantías constitucionales, en aras de lograr una convivencia pacífica y armónica de todas las personas en el Estado colombiano.

La asociación de individuos implica la existencia de un conjunto de normas que regulan sus relaciones cotidianas. Así lo entendían los romanos, quienes acuñaron por aforismo la tesis "ubi homines, ibi societas; ubi societas, ibi ius", que quiere decir: allí donde hay hombres, hay sociedad; donde hay sociedad, hay derecho (Derecho Constitucional, 2012).

La población del territorio colombiano, que conforma una asociación de personas, supone la existencia de reglas o normas de conducta. El sistema normativo colombiano, atravesado en su totalidad por la Constitución Nacional, otorga importancia o valor tanto a los individuos como al conglomerado social, pero predominantemente al individuo, al que se le supone, dicho sea de paso, social por naturaleza, un zoon politikón.

Ahora, con la Constitución de 1991, advirtiendo la importancia del recaudo de fondos para el Estado colombiano, el constituyente previó los principios que orientarían las políticas fiscales hasta nuestros días, a partir de los cuales se derivan garantías para todos y cada uno de los contribuyentes; una de ellas, y en la cual se centrará el análisis del presente estudio, es la irretroactividad de la ley tributaria.

Para abordar el análisis de esta garantía constitucional, es necesario atender a la jurisprudencia desarrollada por el Consejo de Estado, quien es 
el órgano de cierre de la jurisdicción contencioso administrativa, ante la cual se tramitan aspectos atinentes a conflictos suscitados entre el Estado colombiano y sus contribuyentes.

Tal garantía ostenta una importancia suprema, en la medida en que materializa otro principio constitucional, la seguridad jurídica, gracias al cual toda persona puede confiar en la perdurabilidad de las decisiones del legislador y de las actividades administrativas. En materia tributaria, el principio de irretroactividad de la ley tributaria y la seguridad jurídica constituyen, en conjunto, la potestad de toda persona de exigir del Estado coherencia en sus actuaciones y el respeto por los derechos ya adquiridos. La creación, modificación y extinción de derechos en el Estado colombiano no puede ser abrupta e intempestiva, de conformidad con las disposiciones normativas de la Constitución Política de 1991 (CC, Sentencia C-397/11, Colom.).

Desde las miradas cotidianas del ordenamiento jurídico, se tiene establecido que el derecho constitucional, como disciplina académica, está divido en parcelas normativas, características y principios comunes que contempla el derecho civil, mercantil, administrativo, procesal y laboral. Por lo tanto, el derecho público se ejerce en el sector del ordenamiento jurídico que regula el ejercicio de los poderes del Estado, orientado a la procura de intereses colectivos o comunes; sus normas son de carácter obligatorio (derecho administrativo). Por su parte, el derecho privado se ocupará de las normas que regulan las relaciones entre los individuos privados en defensa de sus intereses particulares y se concede un amplio margen de autonomía y voluntad (derecho mercantil, laboral y civil). Todos los llamados de la justicia se hacen inicialmente de los principios consagrados en la Constitución de 1991, que han sido reconocidos por la jurisprudencia como consagrados de una manera implícita. También se 
dice que es innegable su aporte en temas como las irretroactividades de la ley tributaria y algunas rectificaciones a las desviaciones que había tenido la jurisprudencia al respecto.

\section{Hallazgos y resultados}

\section{Constitución como norma de normas}

De la lectura del artículo $4 .^{\circ}$ de la Constitución Política de 1991, claramente se deduce la jerarquía normativa que ostenta la Carta Marga colombiana. La importancia de definir la jerarquía normativa de las normas constitucionales está dada por la necesidad de armonizar la interpretación del ordenamiento jurídico colombiano. En este punto es preciso realizar una puntualización respecto a las normas jurídicas, que se construyen a partir de términos o palabras que hacen parte del lenguaje humano. Este adolece de muchas dificultades como, por ejemplo, la vaguedad, la contradicción, la indeterminación, etc. Las normas jurídicas, debido a que se encuentran construidas con base en el lenguaje humano, padecen de sus mismas dificultades. Por eso, es preciso contar con criterios que limiten el ejercicio interpretativo de todos y cada uno de los términos que conforman cada norma jurídica.

El establecimiento de la Constitución Política de 1991 como norma suprema constituye la positivización, es decir, la consagración normativa del principal criterio a partir del cual se deben interpretar las demás normas que conforman la totalidad del ordenamiento jurídico colombiano. En esta se establece el conjunto de derechos, principios, objetivos y garantías que inspiran al Estado colombiano y, gracias a su jerarquía normativa y a la existencia de mecanismos jurídicos constitucionales en favor de todas las personas, cada individuo puede exigir de la 
Administración Pública el cumplimiento y el respeto por los derechos, principios, objetivos y garantías constitucionales.

Colombia es un Estado social de derecho, de conformidad con lo dispuesto en el artículo 1. ${ }^{\circ}$ de la Constitución Política. Esta denominación no es un simple título, sino que expresa un modelo de organización estatal que gira en torno al individuo, es decir, que valora al individuo como un elemento esencial en el conglomerado social (Motta et ál., 2012).

No siempre fue así. En el modelo previo de organización estatal, conocido como "Estado de derecho", lo que predominaba era el interés general y, en virtud del interés general, los intereses individuales siempre debían ceder. El cambio que se dio con el nacimiento del "Estado social de derecho" es de una importancia enorme, debido a que, con el nacimiento de este modelo estatal, al individuo se le invistió con unas prerrogativas y mecanismos jurídicos que le permiten exigir del Estado la protección de sus intereses individualmente considerados.

Así pues, la Constitución Política de 1991, como norma de normas, no solo contiene un catálogo de derechos y garantías, sino que también cuenta con mecanismos jurídicos expeditos y eficaces para la protección de los derechos fundamentales de todas las personas, como la acción de tutela, la acción popular, la acción de cumplimiento, la acción de grupo, el habeas corpus y el habeas data.

Ahora bien, la Constitución Política no solo contiene un catálogo de principios, derechos, garantías y mecanismos para ejercerlos, sino también un catálogo de deberes y disposiciones que definen la estructura orgánica del Estado colombiano. Todo ese conjunto de disposiciones debe ser atendido por las autoridades que ejerzan la función legislativa, porque de lo contrario las normas proferidas por dichas autoridades se tornan inconstitucionales, motivo por el cual pueden ser expulsadas del 
ordenamiento jurídico colombiano y dejar de producir efectos jurídicos (CC, Sentencia T-406/92, Colom.).

La Carta Magna consagra preceptos de orden constitucional, público y político que establecen las prescripciones reales y procedimentales con relación a conocer, entender y aplicar el derecho en Colombia para una buena convivencia social. Partiendo de esta idea, se puede argumentar y añadir que:

[...] este estatuto de libertades no es solo un listado de derechos, sino también un conjunto de criterios para interpretar y aplicar el resto del articulado constitucional, si se admite, como parece obvio, que la racionalidad finalista de todo el instrumento es garantista o libertaria. (Valencia Villa, 1992, p. 49)

La Constitución es el máximo órgano de representación política que establece los mecanismos para que el ciudadano ejerza y haga efectivo el respeto y cumplimiento de sus derechos fundamentales, partiendo del hecho de que Colombia es un Estado social de derecho.

\section{Definición de Constitución}

El concepto de Constitución no es unívoco. Existen multitud de propuestas teóricas dirigidas a definir este término. Sin pretender incluir todas las conceptualizaciones que teóricos del derecho constitucional han propuesto, podemos describir algunas de las más notables que la definen como un contrato social, en términos de Rosseau (1832); también podemos entenderla como una regla de reconocimiento, en términos de $\mathrm{H}$. L. A. Hart (García, 2010), quien define la regla de reconocimiento como aquella regla última en virtud de la cual se puede saber qué normas pertenecen al ordenamiento jurídico y cuáles no pertenecen a él. 
En Colombia, la Constitución es entendida como un pacto político, es decir, un acuerdo entre diferentes grupos sociales con intereses contrapuestos. Esta connotación política de la Constitución de 1991 ha sido advertida en textos académicos así:

La palabra Constitución y con ella la expresión Derecho Constitucional y cualquier otra en que el término aparezca como adjetivo, se encuentra en su origen ostensiblemente cargada de significado político, evoca de inmediato ideas tales como libertad y democracia, garantía de los derechos de los ciudadanos, limitación de poder. (Cabra, 2007, p. 78)

Este pacto político, gracias a esa jerarquía suprema que ostenta en virtud del atículo $4 .^{\circ}$ constitucional, debe ser respetado por todos los individuos que residen en el territorio colombiano y por el Estado colombiano, y deben observarse todas sus prescripciones normativas en todas y cada una de las conductas desplegadas tanto por el Estado como por las personas que lo conforman.

Con ello, se vislumbra en la Constitución Política de 1991 la consagración normativa de una cultura, de una manera de comportarse de los individuos entre sí, una forma de relacionarse basada en el respeto por la individualidad de cada persona, en el respeto por sus derechos y en el cuidado del entorno que conforma el territorio colombiano.

El ser humano es un ser social por naturaleza, hecho por el cual debe tener unos lineamientos plenamente establecidos de obligatorio cumplimiento; para el caso concreto, partimos del término Constitución, que hace referencia a la ley de leyes que rige el comportamiento normativo de los ciudadanos que conforman la sociedad y que jerárquicamente establece un ordenamiento jurídico y de mandato. 


\section{La Constitución como orden público}

El ordenamiento jurídico colombiano gravita en torno al individuo, pero para que cada sujeto pueda ejercer sus derechos y garantías constitucionales es necesario garantizar un orden público que permita la existencia de las instituciones estatales, cuya razón de ser es la protección de los derechos y garantías de todos y cada uno de los individuos.

El concepto de orden público congloba un conjunto de comportamientos o conductas sociales que cada individuo debe observar en todas sus actuaciones, en aras de mantener una armónica convivencia social. Tal conjunto de comportamientos se inspira en los principios de justicia, equidad y transparencia. Los principios son normas que consagran, ya sea de manera expresa o implícita, mandatos de optimización de la conducta humana, es decir, órdenes para dirigir la conducta de las personas hacia hábitos o costumbres de respeto. Dicho de otro modo, "con el término orden público el ordenamiento jurídico incluye el normal funcionamiento de las instituciones básicas de la sociedad, la paz social y la convivencia pública” (Montalvo, 2010, p. 199).

Los mandatos de optimización o principios consagrados en la Constitución Política de 1991 optan por privilegiar al individuo, pero sin desatender el interés general. En esa medida, el interés general se erige como un límite al ejercicio de los derechos por parte de los individuos. Ese límite está consagrado con el fin de dirigir el comportamiento individual hacia el mayor beneficio para la mayoría, pues dar un valor absoluto al individuo se ha advertido siempre inconveniente a través de los años, exceptuando unas corrientes filosóficas minoritarias que incluso, suponiendo un valor absoluto del individuo, ven el conjunto de normas jurídicas como un instrumento de disociación social en vez de cohesión social. 
Ahora, la Constitución colombiana puede concebirse como un conjunto de normas que regulan la conducta humana, con el fin de garantizar la existencia de un orden público justo que permita a todos y cada uno de los individuos el ejercicio efectivo de todos sus derechos y garantías jurídicas. Dicho de otro modo, la Constitución Nacional es un elemento que une, que invita a unirse a formar parte de la población colombiana; es un elemento que agrupa un conjunto de elementos comunes entre las distintas razas que transitan por el territorio colombiano.

El concepto de orden público hace referencia a los lineamientos que, como miembros de la sociedad, debemos tener en cuenta para una sana convivencia; desde la Constitución, el mismo término nos lleva a las realidades sociales, políticas y jurídicas con una figura de interés general que, a su vez, remite a una especie de limitación relacionada con el comportamiento en términos de justicia, equidad y trasparencia. El orden público puede constituir un límite oponible al ejercicio de las libertades. En todo entorno democrático, el mantenimiento del orden público supone un requisito esencial para preservar el orden social. Con el término "orden público, el ordenamiento jurídico incluye el normal funcionamiento de las instituciones básicas de la sociedad, la paz social y la convivencia pública” (Montalvo, 2010, p. 197).

\section{La Constitución Política: entre lo sustancial y lo formal}

El ordenamiento jurídico colombiano puede distinguir otros dos tipos de normas jurídicas: las sustanciales y las procedimentales. Las primeras consagran derechos y obligaciones; las segundas consagran los procedimientos a través de los cuales se ejercitan los derechos y se cumplen las obligaciones. Entre estos dos tipos de normas, existe una prevalencia de las normas jurídicas de carácter sustancial, de conformidad con lo dispuesto en el artículo 228 de la Constitución Política. 
La prevalencia del derecho sustancial sobre el derecho adjetivo, procedimental o formal tiene una gran importancia práctica, que se acentúa con el fin de que el ordenamiento jurídico colombiano le da al derecho procedimental, pues el fin del derecho procedimental es materializar el sustancial. En otras palabras, la razón de ser de los procedimientos legalmente establecidos es la materialización de derechos; allí se encuentra la justificación de las formas, rituales o procedimientos jurídicos. Según Heller (2002), el Estado vive de su justificación: cada generación, con psicológica necesidad, tiene que plantearse de nuevo el problema de la justificación o consagración del Estado.

La justificación moderna que se le da a los Estados - dicho sea de pasoes el conjunto de derechos fundamentales que estos consagran en sus Constituciones. El respeto por el conjunto de derechos fundamentales se erige como una obligación estatal y su cumplimiento implica el ejercicio de la función pública dentro de estándares de transparencia, equidad y justicia. Lo anterior conlleva que en las actuaciones procesales y procedimentales se busque siempre el cumplimiento y el respeto de los derechos y obligaciones consagrados en las normas sustanciales. El principio de la prevalencia del derecho sustancial sobre el formal está consagrado en nuestra Constitución nacional en el artículo 228; el derecho sustancial consagra en abstracto los derechos, mientras que el derecho formal o adjetivo establece la forma de la actividad jurisdiccional, cuya finalidad es la realización de tales derechos. Esos procedimientos y trámites se conocen como obligaciones formales, que son de forma nada más, pero que en muchos casos son indispensables para dar cumplimiento a la obligación. Desde el modelo de democracia liberal, es necesario "replantearse su justificación; necesita, como se ha señalado, 'relegitimarse'. Esa relegitimación, a nuestro modo de ver, debe venir, sin 
duda, de la transparencia y la responsabilidad como exigencias ineludibles de la gestión pública de nuestro tiempo" (Del Hierro, 2014, p. 185).

\section{La cultura de la legalidad}

La cultura de la legalidad consiste en un comportamiento social estructural y sistemático que respeta el conjunto de obligaciones que las normas jurídicas consagran en cabeza de todos los individuos. El respeto por los preceptos normativos es la base en virtud de la cual se erige el conjunto de derechos de los que se dotan a todos y cada uno de los individuos, en tanto el respeto de las obligaciones implica el respeto de los derechos que le asisten a cada persona.

El respeto por los derechos de todas las personas no solo es una obligación de cada individuo, sino también una obligación del Estado colombiano. Gracias a esta obligación estatal, los servidores públicos deben atender a la justicia y a la equidad en el ejercicio de la función pública, en aras de eludir conductas unilaterales y arbitrarias por parte de la Administración Pública. En definitiva, el respeto por la ley constituye, en sí misma, un deber/derecho tanto de los particulares, individualmente considerados, como de la sociedad en su conjunto, representada por el Estado: deber, porque implica el respeto por los derechos individuales de cada persona; derecho, en tanto implica la facultad de exigir el respeto por el conjunto de derechos que le asiste a cada persona.

Cuando se habla de cultura de la legalidad se pueden entender diferentes cosas, pero principalmente ha de entenderse como un conjunto de comportamientos habituales, constantes y respetuosos de las normas jurídicas (Aldana y Guarín, 2016). Consiste en satisfacer las necesidades y preferencias de la sociedad para generar la seguridad pública y ser parte esencial de la convivencia, mejorar su calidad de vida fundamentada en el 
cumplimiento de la norma, en saberla administrar como un proceso de conocimiento de lo público con equidad y justicia, donde se impide las arbitrariedades y se busca la autorregulación colectiva de la sociedad (Laveaga, 2013).

\section{Discusión}

Una de las responsabilidades consagradas en el artículo 95 de la Constitución Política implica contribuir al financiamiento de los gastos e inversiones del Estado dentro de conceptos de justicia y equidad, pero muchos contribuyentes perciben que su relación de intercambio con el gobierno es injusta, lo que nos lleva a pensar en los diferentes factores; por

ejemplo, la idea de una insuficiente cantidad y calidad de gasto público o la concepción de que el sistema tributario es inequitativo se ve favorecida gracias a los tratos tributarios diferenciales, siendo el caso las deducciones especiales, rentas exentas y descuentos tributarios que permiten que exista una percepción de injusticia en la relación del Estado con la sociedad y favorecen que exista la evasión de impuestos. Es válido señalar la importancia de las estrategias, no solo penales, que se puedan emplear con el fin de promover el cumplimiento tributario, que, en muchos casos, por la percepción que se tiene sobre el manejo de los recursos, la alta desigualdad económica y la poca capacidad redistributiva, se ve reflejado en el incumplimiento y evasión ya mencionados.

La percepción que pueda tener una persona sobre la constitucionalidad del sistema tributario se basa en su experiencia y en la que podría conocer de los demás, lo que se fundamenta en el modo en cómo se calculan y recaudan los impuestos y hace que las personas conciban al sistema impuesto como justo o injusto. Los grados de inequidad concebidos por las personas afectan directamente el grado de recaudación que el gobierno pueda obtener. Al plantear cualquier proyecto de reforma tributaria se 
deben considerar sus efectos en la estructura de equidad del sistema o, si no, podrían conseguir un sistema con una menor aceptación de los contribuyentes, malogrando el potencial tributario del país.

La percepción de los contribuyentes de la equidad, en cuanto a materia tributaria se refiere, depende del trato que reciben los demás en diferentes condiciones económicas. Es más probable que un contribuyente acepte la carga tributaria que por ley le corresponde cuando los demás también cumplen con sus obligaciones. Que un contribuyente considere que los demás evaden no solo es el resultado de observar dicha acción, también puede darse el caso de que se piense que otros evaden porque pagan pocos impuestos, aunque ello se deba a los beneficios tributarios que los cobijan (Bolaños, 2017).

Un individuo podría concluir que el sistema tributario que lo cubre no es imparcial por diferentes razones, como por ejemplo encontrar que la carga tributaria de otros ciudadanos con una capacidad de pago igual no se calcula siguiendo los mismos criterios. La percepción de justicia sobre la imposición de una obligación, como lo es un impuesto, depende del grado de aprobación del mecanismo que se siguió para determinar los compromisos fiscales de los demás.

La ideología política de un ciudadano se asocia con el grado de aceptación que le merece la obligación constitucional de pagar impuestos, en la medida en que la primera capture su percepción sobre la necesidad de la intervención estatal; si una ideología política se asocia con un interés redistributivo y una contraria no lo hace, entonces es de esperar que el individuo apoye la ideología que es más cercana a sus intereses políticos. La confianza en el gobierno contribuye a que el intercambio tributario se considere justo y, con ello, se promueva el cumplimiento tributario. El sistema tributario, siendo fuente de ingresos de un país, no es en sí el 
problema para los colombianos, puesto que por medio de este se financia el Estado para los diferentes programas sociales e inversión en infraestructura, seguridad, salud y educación, entre otros. Aunque esto es un beneficio para todos, de cierto modo pequeños empresarios e independientes se ven afectados por todo lo relacionado con los impuestos, dado que estos en muchas ocasiones tienen montos altos interfiriendo en las actividades que ellos realicen.

La tributación la deben cumplir tanto personas naturales como jurídicas y, aunque en la mayoría de los casos no están de acuerdo con todo lo relacionado con el pago de tributos, lo deben hacer, ya que el incumplimiento de estas obligaciones acarrea sanciones. La carga fiscal que deben asumir los pequeños contribuyentes en Colombia conlleva una situación adversa, afectando la parte financiera dentro de las pequeñas empresas; en consecuencia, también se ven afectados los niveles de sostenibilidad, desarrollo y competitividad, debido a que nuestro sistema tributario es complejo y existen altas tasas impositivas además de la cantidad de estos tributos.

El desarrollo económico de un país se encuentra asociado al aumento de su producto nacional bruto y al incremento de la renta per cápita, lo que tiene que ver mucho con el aumento de las utilidades de las empresas. Por tal razón, cuando los tributos son excesivos, los recursos disponibles disminuyen, lo que lleva a su vez al pago de menos impuestos o al aumento de acciones de evasión tributaria, lo que merma el ingreso de recursos estatales para el cumplimiento de sus políticas de desarrollo. Se puede afirmar que el aumento en el grado de tributación debilita el crecimiento económico (Parra, 2007). 


\section{Conclusiones}

Con base en los hallazgos del estudio, a continuación, presentamos las principales conclusiones:

- La Constitución determina las personas que son titulares de los poderes de imposición, sus límites y sus principios, y también los deberes y derechos de todos los ciudadanos, así como las obligaciones de las personas que deben contribuir al financiamiento de los gastos e inversiones del Estado, teniendo en cuenta los conceptos de justicia y equidad.

- Los impuestos constituyen el principal sustento de un Estado, por lo que los intereses del gobierno deben ser afines a los de los ciudadanos. La importancia de pagar tributos reside en que, con estos aportes, los colombianos contribuimos a garantizar la sostenibilidad fiscal del Estado. A su vez, esto posibilita que el gobierno provea bienes públicos para el beneficio de todos, tales como carreteras, escuelas, hospitales, etc. La Constitución, norma de normas, tiene establecido que les corresponde a los ciudadanos el financiamiento de los gastos e inversiones de la nación. Con base en esta premisa, se da el origen constitucional de la creación de los tributos.

- La mayoría de personas en el país tiene en su conciencia que los Estados necesitan de los impuestos para financiase y realizar las inversiones, en especial en el ámbito social. Lo esperable es que estos sean justos con los ingresos de los ciudadanos y, a la vez, se inviertan de manera eficiente y eficaz, para no tener la percepción de que se los roban. Los países necesitan recursos para su adecuada sostenibilidad, pero los impuestos deberían ser consecuentes con el nivel de ingreso de cada nación. 
- La corrupción limita la provisión pública de bienes y servicios para beneficiar solo a determinados agentes, lo que favorece la evasión.

- Estudiar el tema relacionado con el sistema tributario deja mucho que analizar para todos los contribuyentes, dado que, en muchas ocasiones debido a la carga fiscal, se evidencia abusos y corrupción por parte del gobierno, afectando notablemente el crecimiento de este país. Sin duda, mantenerse enterado de los cambios tributarios, de las reformas y demás es una estrategia que no solo ayuda a llevar un seguimiento de lo que realmente se debe pagar, sino que, más importante aún, nos lleva a tomar las mejores e indicadas opciones de inversión.

Recordemos que hay vehículos de inversión que minimizan el pago de nuestros impuestos, por ejemplo, los fondos de pensiones voluntarias.

- Por su parte, el estatuto tributario posee un conjunto de normas encargadas de regular la mayoría de los aspectos relacionado con el recaudo de impuestos y determina aquellas personas que deben pagar tributos de acuerdo con los hechos generadores de impuestos, es decir, aquellos que tengan la capacidad de pagarlos.

- El sistema tributario colombiano presenta una inequidad, dejando en desventaja a los pequeños contribuyentes. Artículos como el 499 y el 506 del Estatuto Tributario crean una brecha entre pequeños y grandes contribuyentes, ya que es inequitativo a la hora de calcular los tributos; no obstante, estos están creados con el fin de ejercer un control y también presentan algunas ventajas para el pequeño contribuyente, pero al mismo tiempo crea una brecha y se convierte en responsable de los déficits fiscales del país, debido a que el pequeño contribuyente prefiere evadir impuestos que participar de esta brecha.

- La legislación tributaria tiene mucha relevancia en la distribución de los ingresos de los ciudadanos y, por lo tanto, deben existir normas que garanticen la equidad en su recaudación y que todos los ciudadanos 
contribuyan de acuerdo con sus posibilidades. Se puede concluir que el Gobierno, tratando de controlar la evasión de impuestos y reducir el régimen fiscal, no ha tenido en cuenta las consecuencias que esto genera a los pequeños contribuyentes $y$, por ende, a los empresarios en general.

\section{Referencias}

Aldana, J. y Guarín, E. (2016) Los límites de la teoría del equilibrio como alternativa de solución a la cuestión de la prevalencia del poder del Alto Tribunal de lo Constitucional en Colombia. Revista Via Inveniendi et Iudicandi, 11(1), 59-82. https://doi.org/10.15332/s1909-0528.2016.0001.01

Barragán, D. (2016). La construcción de la mentalidad democrática como necesidad en el posconflicto. Revista Via Inveniendi et Iudicandi, 11(1) 37-57. https://doi.org/10.15332/s1909-0528.2016.0001.06

Bolaños Bolaños, L. (2017). Justicia tributaria como principio constitucional en el Estado social de derecho. Revista de Derecho, 48, 54-81. http://rcientificas.uninorte.edu.co/index.php/derecho/article/viewArticle/8374/11 $\underline{117}$

Cabra, M. G. (2007). Ensayos de teoría constitucional y derecho internacional. Universidad del Rosario.

Castro Jaramillo, A. M. (2016). Derecho a la intimidad en las redes sociales de Internet en Colombia. Novum Jus, 10(1), 113-133. https://doi.org/10.14718/NovumJus.2016.10.1.5

Constitución Política de Colombia [CP]. Julio 7 de 1991 (Colom.).

Corte Constitucional de Colombia [CC], junio 5, 1992, MP: C. Angarita Barón, Sentencia T406/92, [Colom.].

Corte Constitucional de Colombia [CC], mayo 18, 2011, MP: J. I. Pretelt, Sentencia C397/11, [Colom.].

Cubides Durán, E. (2018). Simplificación tributaria territorial en Colombia. Revista de Derecho Fiscal, 12, 171-218. https://doi.org/10.18601/16926722.n12.08 
Dahl, R. A. (1999). The Past and Future of Democracy. CIRCAP.

Del Hierro, J. L. (2014). Legitimidad y legalidad. EUNOMÍA. Revista en Cultura de la Legalidad, marzo-agosto, 179-186.

Derecho constitucional. (2012, 29 de julio). El derecho y los derechos. https://www.derechoconstitucional.es/2012/01/el-derecho-y-los-derechos.html

Galán Galindo, A. R. (2017). Entre justicia y moralidad: criterios metateóricos en cuanto a la justicia la moral y el Derecho. Novum Jus, 1O(2), 103-118.

https://doi.org/10.14718/NovumJus.2016.10.2.6

García, R. (2010). La regla de reconocimiento de HLA Hart.

Heller, H. (2002), La justificación del Estado. Universidad Nacional Autónoma de México.

Jiménez, J. (1988). "Derecho constitucional. Sistema de fuentes", de Ignacio Otto [reseña del libro Derecho constitucional: sistema de fuentes de I. Otto. Revista Española de Derecho Constitucional, 8(23), 305-322.

Laveaga, G. (1999). La cultura de la legalidad. Universidad Nacional Autónoma de México, Instituto de Investigaciones Jurídicas.

Mesa, N., A. G. (2016). Una mirada histórica empresarial y su comportamiento en las finanzas públicas de los periodos comprendidos entre el 2012 y 2017. Colombia.

Montalvo, J. (2010). Concepto de orden público en las democracias contemporáneas. RJUAM, 22, 197-222.

Motta Navas, A.,Suelt Cock, V. y Corrales Sánchez, M. S. (2012). La importancia de la jurisprudencia en Colombia. Deutsche Gesellschaft für Internationale Zusammenarbeit (GIZ).

https://metodosderesoluciondeconflictos.files.wordpress.com/2014/07/07_impor t jurisp_col.pdf

Parra, A. (2007). Planeación tributaria y organización empresarial. Legis.

Romero-Molina, C. A., Grass-Súarez, Y. C. y García-Caicedo, X. C. (2013). Principios constitucionales que rigen el sistema tributario. DIXI, 15(17), 67-77. https://doi.org/10.16925/di.v15i17.640

Rodríguez, R. (2008). La tradición liberal. En: Ciudad y ciudadanía. Senderos contemporáneos de filsofía política. Trotta. 
Rousseau, J. J. (1832). El contrato social, o Principios del Derecho político.

Pastor, M. L. S. (2015). Clima institucional y desempeño docente en los centros de educación básica alternativa del distrito de Abancay, 2013 [Tesis de maestría, Universidad César Vallejo]. https://hdl.handle.net/20.500.12692/6970

Uvalle, R. (2006). Las políticas públicas en el gobierno de la democracia. En J. C. León y S. Mora, Ciudadanía, democracia y políticas públicas (pp. 299-326). Universidad Nacional Autónoma de México.

Valencia, H. (1992). Los derechos humanos de la Constitución del 91. Estudios Políticos, 2, 45-61.

Welte, B. (2004). La idea del nuevo humanismo y la dialéctica de integración y progreso.

Revista Ciencia y Cultura, 14, 83-93.

http://www.scielo.org.bo/scielo.php?pid=S2O77-

$33232004000100007 \&$ script $=$ sci $\_$arttext\&tlng $=$en

Revista IUSTA

ISSN: 1900-0448 | e-ISSN: 2500-5286 | DOI: https://doi.org/10.15332/25005286

N. ${ }^{\circ} 54$ | enero-junio de 2021 